\title{
Scale-dependent response diversity of seabirds to prey in the North Sea
}

\author{
Per Fauchald, ${ }^{1,6}$ Henrik Skov, ${ }^{2}$ Mette Skern-Mauritzen, ${ }^{3}$ Vera Helene Hausner, ${ }^{4}$ David Johns, ${ }^{5}$ \\ AND TORKILD TVERAA ${ }^{1}$ \\ ${ }^{1}$ Norwegian Institute for Nature Research (NINA), Arctic Ecology Department, Polar Environmental Centre, \\ N-9296 Tromso, Norway \\ ${ }^{2}$ DHI, Agern Alle 5, DK-2970 Hørsholm, Denmark \\ ${ }^{3}$ Institute of Marine Research, N-5817 Bergen, Norway \\ ${ }^{4}$ University of Tromso, Department of Arctic and Marine Biology, N-9037 Tromsø, Norway \\ ${ }^{5}$ Sir Alister Hardy Foundation for Ocean Science (SAHFOS), The Laboratory, Citadel Hill, \\ Plymouth PL1 2PB United Kingdom
}

\begin{abstract}
Functional response diversity is defined as the diversity of responses to environmental change among species that contribute to the same ecosystem function. Because different ecological processes dominate on different spatial and temporal scales, response diversity is likely to be scale dependent. Using three extensive data sets on seabirds, pelagic fish, and zooplankton, we investigate the strength and diversity in the response of seabirds to prey in the North Sea over three scales of ecological organization. Two-stage analyses were used to partition the variance in the abundance of predators and prey among the different scales of investigation: variation from year to year, variation among habitats, and variation on the local patch scale. On the year-to-year scale, we found a strong and synchronous response of seabirds to the abundance of prey, resulting in low response diversity. Conversely, as different seabird species were found in habitats dominated by different prey species, we found a high diversity in the response of seabirds to prey on the habitat scale. Finally, on the local patch scale, seabirds were organized in multispecies patches. These patches were weakly associated with patches of prey, resulting in a weak response strength and a low response diversity. We suggest that ecological similarities among seabird species resulted in low response diversity on the year-to-year scale. On the habitat scale, we suggest that high response diversity was due to interspecific competition and niche segregation among seabird species. On the local patch scale, we suggest that facilitation with respect to the detection and accessibility of prey patches resulted in overlapping distribution of seabirds but weak associations with prey. The observed scale dependencies in response strength and diversity have implications for how the seabird community will respond to different environmental disturbances.
\end{abstract}

Key words: biodiversity; Calanus; Common Murre, Uria aalge; ecosystem resilience; herring, Clupea harengus; Kittiwake, Rissa tridactyla; krill; sprat, Sprattus sprattus; zero-inflation.

\section{INTRODUCTION}

Anthropogenic drivers steadily transform ecosystems into less diverse, impoverished systems (Sala et al. 2000). How the loss of biodiversity is related to ecosystem functioning has therefore become a central topic for the maintenance of ecosystem services (Loreau et al. 2001, Naeem 2002, Hooper et al. 2005). Evidently, it is necessary to disentangle the functional role of different species, and to preserve groups of species with important functional roles. The diversity of species that contribute to the same ecosystem function has been argued to be an important property for ecosystem resilience (Pimm 1982, Elmqvist et al. 2003, Folke et al. 2004). This is because high diversity makes it more likely that some species

Manuscript received 25 April 2010; revised 18 June 2010; accepted 18 June 2010. Corresponding Editor: E. G. Cooch.

${ }^{6}$ E-mail: per.fauchald@nina.no might compensate for the loss of others following environmental disturbances (Naeem 1998). Diversity in the response to environmental changes will increase the probability of compensation for the loss of key species, and thereby secure the continuation of an ecosystem function. Response diversity is accordingly defined as the diversity of responses to environmental change among species that contribute to the same ecosystem function (Elmqvist et al. 2003).

Cross-scale resilience might arise because different species operate on different spatial and temporal scales (Holling 1992, Elmqvist et al. 2003). However, an additional and possibly equally important factor arises because different ecological processes are likely to dominate at different spatial and temporal scales (Levin 1992). As a consequence, responses to environmental heterogeneity are likely to change across scales, and the diversity of responses within a functional group could also be expected to be scale-dependent. Three different 
outcomes are possible. First, direct interspecific interactions between individuals, such as facilitation or interference competition, can create small-scale pattern in the distribution of species, irrespective of the external environment. In such cases, the distribution of species will be aggregated or segregated, but the relative effect of the environment will be small, and the diversity in responses to environmental heterogeneity will be low. Direct interactions between individuals are likely to operate on small spatial scales, and among mobile animals they are likely to occur on short time scales. Second, often at larger scales, interspecific competition might have resulted in specialization and niche segregation among species within a functional group. Different habitat utilization and specialization will result in different responses to environmental heterogeneity; response diversity will therefore be high and the average effect of the environment will be low. In this case, high response diversity might secure ecosystem functioning under an external perturbation. Third, species within a functional group will, by definition, possess some similar traits which inevitably make them sensitive to the same environmental variables. At a given scale, different species might therefore respond similarly to environmental heterogeneity, resulting in low response diversity. A synchronous response will give a strong average effect of the environment, making the system more vulnerable to external perturbations. To assess the vulnerability of a functional group to external perturbations, it is therefore necessary to disentangle the various scale-dependent processes that contribute to response diversity.

In this study we explore the response diversity of pelagic seabirds to prey in the North Sea over three different scales: the year-to-year scale, the habitat scale and the local patch scale. Pelagic seabirds belong to the larger functional group that constitutes the top predators of marine pelagic ecosystems. They consume small pelagic fish and crustaceans. High mobility makes them able to operate on a range of spatial and temporal scales in the search for food (e.g., Fauchald et al. 2000, Fauchald and Tveraa 2006). We concentrate on the nonbreeding period when the movements of birds are less constrained by the location of the breeding colony, and combine three extensive spatial data sets on seabirds, pelagic fish and zooplankton. The data sets cover the entire North Sea in multiple years. The variance in abundance of different species is partitioned among three different scales of investigation. On the year-toyear scale, we investigate how yearly changes in the North Sea ecosystem affect the abundance of different seabird species. On the habitat scale we investigate how different seabird species are distributed among habitats. On the local patch scale we investigate how different seabird species aggregate on local patches of prey. Because different ecological processes are expected to dominate on the different scales, we expect that the response diversity will change across scales. On the yearto-year scale, we expect that the response diversity will reflect how general ecosystem properties affect the suitability of the North Sea as a winter area. On the habitat scale, we expect that the response diversity is related to interspecific competition and species-specific adaptation to different food sources (Ballance et al. 1997). On the local patch scale we expect the response diversity to be related to the spatial behavioral game between predators and prey (Fauchald 2009).

\section{Materials And Methods \\ Study area and data sets}

Seabirds.-Data on seabirds were extracted from the European Seabird at Sea (ESAS) database. Data were collected by standardized strip transect methodologies (Tasker et al. 1984). All seabirds observed within an arc with a radius of $300 \mathrm{~m}$ extending from directly ahead to $90^{\circ}$ to one side of the ship were counted while steaming at a constant speed. Bird surveys were carried out from ships of opportunity. We used data from the winter period (1 October-31 March) from 1981 to 1999. The surveys had a total length of $148269 \mathrm{~km}$ and 65 different seabird species were observed during the surveys. In the analyses, we included the 10 most abundant and pelagic species. Pelagic, diving species included were Common Murre (Uria aalge, 64258 observations); Razorbill (Alca torda, 27824 observations); Little Auk (Alle alle, 7800 observations); and Atlantic Puffin (Fratercula arctica, 2000 observations). The plunge-diving pelagic species included was Northern Gannet (Morus bassanus, 9433 observations). Surface-feeding pelagic species included were Northern Fulmar (Fulmarus glacialis, 61816 observations) and Black-legged Kittiwake (Rissa tridactyla, 53750 observations). Coastal surface-feeding species included were Herring Gull (Larus argentatus, 64443 observations); Great Black-backed Gull (Larus marinus, 30801 observations); and Common Gull (Larus canus, 21584 observations). Following continuous transects chronologically, the counts of each seabird species were summed up along $20 \mathrm{~km}$ long strips. The midpoint of each strip was used as location. To retain as much of the data as possible, end of transects $(>5 \mathrm{~km})$ and short transects $(>5 \mathrm{~km})$ were also included in the data set. The count of seabirds on each strip was used as sampling unit.

The detectability of seabirds within strips did potentially vary with a number factors such as distance from transect line, type of vessel, observer, light, and weather conditions. Variable practice with respect to the recording of these factors made them impossible to control for in the analyses without discarding a large proportion of the data. However, a simple standardized methodology, and the fact that the analyses only included common species which are relatively easy to identify, suggest that this error was reduced to a minimum. Based on the large data set at hand, we assumed that the error due to detectability was equally distributed among areas and years. Moreover, due to different size, color and behavior, different seabird 
species varied in their detectability. Specifically, small diving auks were probably under-estimated while gulls and fulmars that tend to follow the ship were overestimated. It should therefore be noted that the abundance estimates presented are relative values.

Pelagic schooling fish.-The major trophic link between zooplankton and top predators in the North Sea is occupied by a few small pelagic schooling fish species. Potentially important food items for seabirds are sandeel (Ammodytes marinus), herring (Clupea harengus), and sprat (Sprattus sprattus) (see e.g., Camphuysen 1990, Camphuysen and Webb 1999, Skov et al. 2000). In the present study, we concentrated on the two latter species. Sandeel occupy shallow areas with sandy bottom and is a highly important forage species for top predators in the North Sea (e.g., Frederiksen et al. 2005). However, during winter this species is mainly inactive and buried in the substrate. Sandeel was therefore not included in the present study. Sprat is a small $(<20 \mathrm{~cm})$ pelagic schooling fish with a short life span (4-5 years). It is harvested in an industrial trawl fishery with huge variations in catches over the last 30 years (ICES 2007). Herring is a slightly larger species $(<25 \mathrm{~cm})$ with a longer life span $(<15$ years $)$. Historically, North Sea herring has been the target of an important European fishery (e.g., Alheit and Hagen 1997, ICES 2007).

We used data from the International Bottom Trawl Survey (IBTS). Data were obtained from the DATRAS (database trawl surveys) database operated by the International Council for the Exploration of the Seas (ICES). The North Sea IBTS data are described in detail in ICES (2004). Initially, the IBTS survey was designed to measure the distribution and abundance of young herring. Due to the shallow water column of the North Sea, the survey sample both benthic and pelagic fish species. The catchability of important prey species to seabirds, including herring and sprat, is considered to be relatively good (see, e.g., Skov et al. 2000). We used data from the same time period as the seabird data: 19811999. Trawl haul was used as sampling unit in the analyses, and the midpoint of the trawl was used as location. CPUE (catch per unit effort, the number of fish caught per hour of trawling) was used as a proxy for density.

Different fishing gears have been used by the different participants of the IBTS survey. However, from 1984 all participants used the 36/47 Grande Ouverture Verticale (GOV) trawl. In the period 1981-1983 two other fishing gears were included in the analyses. Because catchability depends on fishing gear, the type of fishing gear was included as a factor in the analyses.

Zooplankton.-The planktivorous bird fauna of the North Sea is dominated by Fulmars and Little Auks. The Little Auk is known to favor larger zooplankton species of high caloric value (Bradstreet and Brown 1985), while the Fulmar exploits a wider range of food items (Cramp and Simmons 1977). High abundance of zooplankton might also indicate high biological productivity, and they might therefore indirectly be important for a range of seabird species. We used data from the Continuous Plankton Recorder (CPR) survey provided by the Sir Alistair Hardy foundation (Plymouth, UK). Detailed description of the sampling routine is found in Richardson et al. (2006). The CPR is a highspeed sampler that is towed behind merchant ships on their routine, monthly trading routes. The device filters seawater at a depth of 7-9 $\mathrm{m}$ on a moving band of silk. After each tow the silk is divided into samples where each sample represents approximately 10 nautical miles $(18520 \mathrm{~m})$ of towing and $3 \mathrm{~m}^{3}$ of filtered seawater. Each sample is counted with respect to plankton and the samples are positioned and dated (Richardson et al. 2006). In the present study we used data from the winter period (1 October-31 March) from 1981 to 1999. The count of zooplankton from each sample was used as a proxy for zooplankton density, and the midpoint of the sample was used as location. We included three groups of copepods; Paracalanus spp. and Pseudocalanus spp. (hereafter termed Para/pseudocalanus), Calanus helgolandicus (stages CV-CVI), and C. finmarchicus (stages CV-CVI). In addition we included krill Euphausiacea spp. (juveniles and adults) dominated by Meganyctiphanes norvegica (Lindley 1982). It should be noted that Para/pseudocalanus probably is too small to be an important food item for seabirds, and it will therefore mainly have an indirect effect.

Summary of sample size and spatial distribution of observations for each database and year is found in Appendix A, Table A1.

\section{Analyses}

In order to investigate numerical interactions on different levels of ecological organization, it is necessary to partition the variance into appropriate scales (Fauchald et al. 2000, Ciannelli et al. 2008). This is because a pattern generated by an ecological process at a particular scale will be masked by pattern generated by other processes at both larger and smaller scales (Fauchald et al. 2000). Thus, to identify a large-scale process, one has to remove the noise from small-scale processes by aggregating or smoothing the data. Similarly, in order to identify a small-scale process one has to remove the masking effect of large-scale processes by identifying and controlling for them in the analyses (Ciannelli et al. 2008). To accomplish this task, we fitted the data of each species group of seabirds, fish and zooplankton to a statistical model where year and geographically fixed variables were used as predictors (Fig. 1). The geographically fixed predictors included: position in UTM 32 coordinates; bottom depth, derived from the ETOPO 2v2 global relief model (available online) ${ }^{7}$ and distance to coast, calculated as the

\footnotetext{
${ }^{7}\langle$ www.ngdc.noaa.gov/mgg/global/etopo2.html $\rangle$
} 


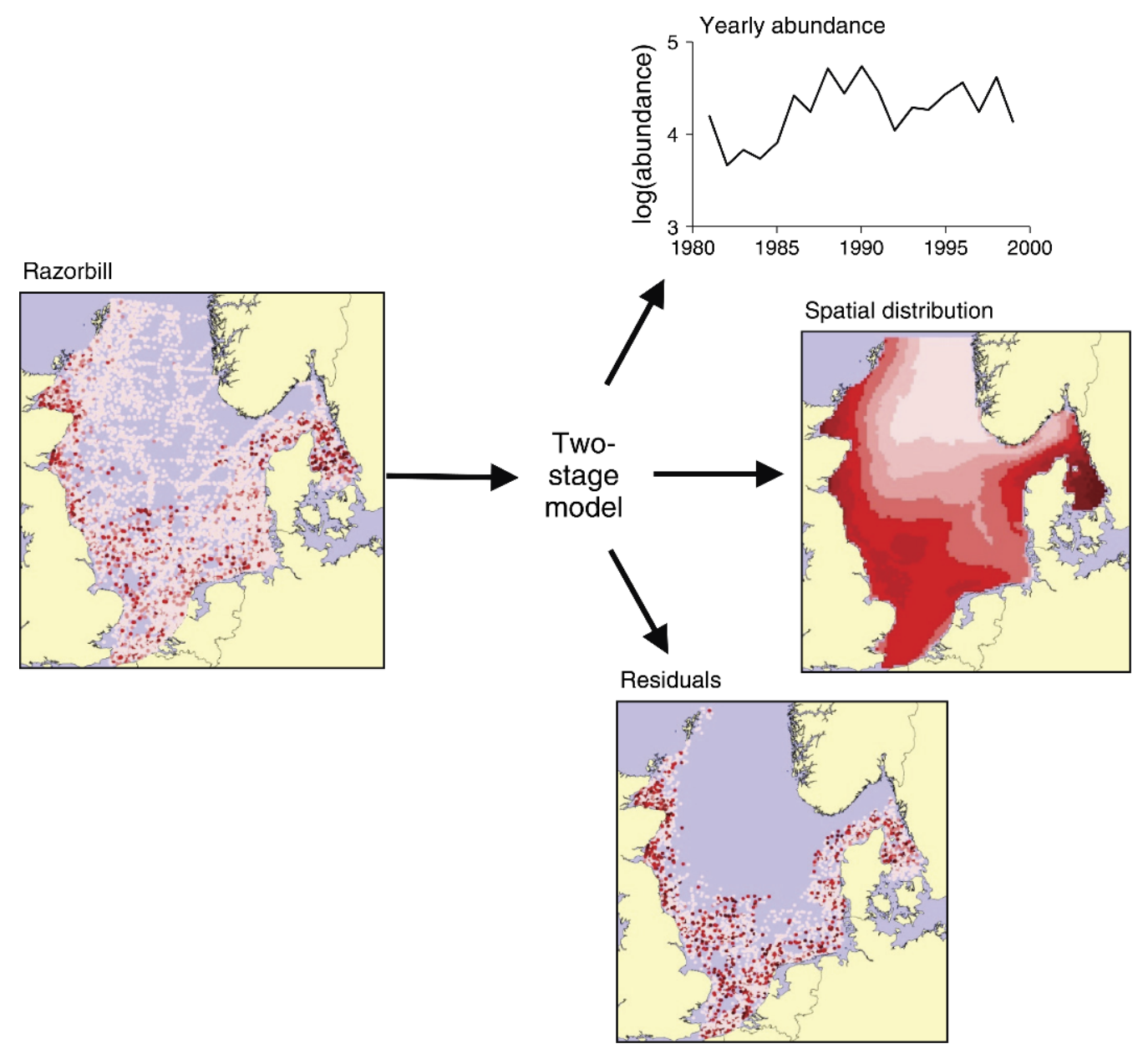

FIG. 1. The partitioning of variance among scales. The data from each species group (in this case Razorbill; Alca torda) was modeled by a two-stage statistical model (see Methods) where the count of each species was used as response variable, and year, position, bottom depth, and distance to coast were used as predictors. The model predicted yearly abundance and the average spatial distribution within the study area. The predicted yearly abundance (number of birds) and spatial distribution for all species groups are shown in Appendix B. The residuals from the model were used to investigate small-scale patch dynamics. Note that observations with low probability of presence were removed from the residuals.

minimum distance between the observation and the coast line. Based on these models, we predicted the yearly abundance and the average spatial distribution for each species group. In addition the residuals from the models were extracted. We suggest that the year-toyear variation in the abundance of pelagic fish and zooplankton reflects general changes in the North Sea ecosystem. By relating the predicted yearly abundance of seabirds to that of their prey, we investigated the response of seabirds to prey on the year-to-year scale. Controlled for yearly abundance, the average spatial distribution of different prey groups reflects the potential habitats available to seabirds. By relating the predicted general distribution of prey to the habitats occupied by the different seabird species, we investigated the response of seabirds to prey on the habitat scale. Finally, the residuals represent the variance not accounted for by the models. This includes (1) year-to-year changes in spatial distribution, (2) small-scale patch dynamics within years, and (3) measurement error. The relationship between the residuals of seabird and prey will accordingly, to some degree, reveal how seabirds aggregate on patches of prey and how prey in turn responds to this aggregative behavior.

It should be noted that while the responses on the yearto-year and habitat scales were based on model predictions, the responses on the local patch level were based on all residual noise which inevitably will reduce the strength of the measured responses. It should also be noted that the three data series were not collected synoptically. While this was of minor importance for the measured responses on the year-to-year and habitat scales, it limited the smallest spatial and temporal resolution that could be investigated on the local patch level.

Two-stage modeling.- - As a direct consequence of its patchy nature, spatial data on zooplankton, fish, and 
seabirds do frequently include an excess of zeroes (Ciannelli et al. 2008). Two-stage modeling is an effective way of dealing with zero-inflated data (Welsh et al. 1996, Barry and Welsh 2002, Zuur et al. 2009). First, presence/absence is modeled with a binomial distribution. Second, the counts of individuals, conditional on presence, is modeled with a truncated Poisson or negative binomial distribution (Welsh et al. 1996). Possibly due to a large number of high counts in the data sets, models with truncated negative binomial and Poisson distributions did frequently fail to converge. We therefore opted to model the counts using a Gamma distribution with a log link (Fox et al. 2000). We used generalized additive models (GAM) from the "mgcv" library (Wood 2006) in R v.2.10.1 (R Development Core Team 2009) to model the count data from each species group. Average spatial distribution was modeled with three geographically fixed covariates: the geographical location in the $x$ (west-east) and $y$ (south-north) direction, bottom depth $(d)$ and distance from coast $(c)$. Geographic position was modeled with a two-dimensional smooth function; $g(x, y) . d$ and $c$ were modeled with a one-dimensional smooth function; $s(\cdot)$. We used tensor product smoothes with cubic regression spline as basis. The optimal degree of smoothing was defined by generalized cross validation (GCV). Year $(A)$ and fishing gear $(F)$ (fish only) were modeled as categorical variables. Due to variable transect lengths, $\log _{e}($ transect length) was included as an offset in the analyses of seabirds. First, the probability of counts larger than zero ( $p$ ) was modeled using a logit link with a binomial distribution:

$$
\operatorname{logit}(p)=A+F+g(x, y)+s(d)+s(c) .
$$

Second, the count $n$ given the presence of a non-zero count, was modeled using a $\log _{e}$ link with a Gamma distribution:

$$
\log _{e}(E\{n \mid \text { presence }\})=A+F+g(x, y)+s(d)+s(c)
$$

where $E$ is expectation.

Model predictions.-Based on the fitted models, we used the "predict" function in the "mgcv" library to predict the average spatial distribution on a $10 \times 10 \mathrm{~km}^{2}$ grid covering the entire study area in each year (cf. Fig. 1). Accordingly, the predicted probability of a non-zero count $\left(\hat{p}_{i, y}\right)$ in grid cell $(i)$ and year $(y)$ was derived from the binomial model (Eq. 1). Similarly, the expected count when present $\left(\hat{n}_{i, y}\right)$ was predicted from the Gamma model (Eq. 2). The predicted count in a grid cell is then given by $\hat{U}_{i, y}=\hat{p}_{i, y} \hat{n}_{i, y}$ (Barry and Welsh 2002). Predicted yearly abundance was calculated as $\hat{Y}_{y}=$ $\Sigma_{i} \hat{U}_{i, y}$, and predicted average spatial distribution was calculated as $\hat{H}_{i}=\operatorname{mean}_{y}\left(\hat{U}_{i, y}\right)$.

Residuals.-On the local patch level, we were interested in the spatial dynamics within the major habitats (see, e.g., Fauchald et al. 2000, Ciannelli et al. 2008).
Thus, to derive the pattern on the local patch scale, we reversed the two-stage approach. First, the binomial model (Eq. 1) was used to delineate the major habitats by removing all observations with $\hat{p}<\operatorname{median}(\hat{p})$. This secured that analyses on the local patch scale were only conducted in areas with high density (cf. Fig. 1). Second, based on the Gamma model (Eq. 2), we derived the Gamma residuals from all remaining observations. Thus, the residual $R_{j}$ in observation $j$ with observed count $x_{j}$ was given by

$$
R_{j}=\frac{x_{j}-\hat{n}_{j}}{\hat{n}_{j}}
$$

when

$$
\hat{p}_{j} \geq \operatorname{median}(\hat{p}) .
$$

Note, that the cut-off in Eq. 3 was set arbitrarily. Analyses of spatial structure (see next section) were used to justify this cut-off rule.

Analyses of spatial and temporal pattern in data and residuals. - To investigate the performance of the twostage models and the spatial and temporal pattern of the residuals, we analyzed the autocorrelation structure of the data and residuals. Because the data sets in each year were collected within a time period covering at least one month and because several ships collected data simultaneously, we were able to calculate spatial autocorrelograms within a maximum time lag as well as temporal autocorrelograms within a maximum spatial distance. Thus, for the spatial autocorrelograms, only pairs of observations with a time lag of less than 6 days were included. For the temporal autocorrelograms, only pairs of observations with a distance of less than $50 \mathrm{~km}$ were included. The spatial and temporal autocorrelograms allowed us to assess the performance of the models as well as the spatial scale and duration of pattern inherent to the residuals. The autocorrelograms were based on Pearson's product moment correlation coefficients. Due to skewed distributions, both data and residuals were $\log _{e}$-transformed prior to analyses. Because the residuals could take values larger than or equal to -1 (cf. Eq. 3), the residuals were added a value of 1.01 before logtransformation. Analyses were programmed in SIMULA (Kirkerud 1989).

Response strength, response diversity, and seabird correlation.-We used the Pearson's product-moment correlation coefficient $\left(r_{s t}\right)$ as a measure of the response strength of seabird $(s)$ to prey $(t)$. For each level of organization, the data consisted of the responses of 10 seabird species to six prey groups. On the year-to-year scale, the $r_{s t}$ values were calculated from the predicted values of yearly abundance; $\log _{e}\left(\hat{Y}_{y}\right)$. Predicted values of seabirds were matched with prey giving an effective sample size of 19 years from 1981 to 1999. On the habitat scale, responses were calculated from the predicted average spatial distributions; $\log _{e}\left(\hat{H}_{i}\right)$. In each grid cell, the predicted counts of seabirds were matched 
with the predicted counts of prey. The grid consisted of 5489 grid cells. However, the effective sample size on the habitat scale was determined by the effective degrees of freedom (edf) from the smoothing with respect to position, depth, and distance to coast in the two-stage models. Total edf of the smooth terms varied from 21.1 to 31.0 (Appendix B: Table B1). Covariance between the predictors could potentially bias the results on the habitat scale. However, the correlations between the predictors were generally low (Pearson's $r$ from -0.21 to 0.15 ), except for the correlation between position in the $y$-direction and bottom depth $(r=0.75)$; meaning that bottom depth increased to the north. The two-dimensional smooth term of position contributed with the majority of the edfs: ranging from 14.9 to 23.8 (Appendix B: Table B1), and explained the major part of the variation in spatial distribution. We decided nevertheless to include bottom depth and distance to the coast, as these variables were presumably better at predicting the distribution of coastal species and specific responses to the Norwegian trench. On the local patch scale, the responses were calculated from the residuals of predator and prey: $\log _{e}(R+1.01)$. The residuals of seabirds and prey were matched by time and position. From all possible pairs, only pairs with a distance less than $50 \mathrm{~km}$ and a time lag less than 7 days were included. This matching rule was determined on the basis of the scales indicated by the spatial and temporal autocorrelograms of the residuals (see above). According to these analyses, spatial structures where generally larger than $50 \mathrm{~km}$ and lasted longer than 7 days. Because the residuals in areas of low probability of presence (Eq. 3) had been removed, the numbers of pairs varied from 93 to 3949 depending on overlap in habitat and data set.

Given the average response strength of all seabirds to prey group $t\left(\bar{r}_{t}\right)$, the average response strength (RS) across all prey groups was defined as

$$
\mathrm{RS}=\operatorname{Mean}\left[\operatorname{abs}\left(\bar{r}_{t}\right)\right] .
$$

Response diversity (RD) of seabirds to all prey groups was defined as the variance in $r_{s t}$ corrected for $\bar{r}_{t}$ :

$$
\mathrm{RD}=\operatorname{Var}\left(r_{s t}-\bar{r}_{t}\right) .
$$

To measure the covariance among seabirds, we calculated the average seabird correlation (SC), defined as the average of the seabird correlation matrix.

Confidence intervals for the RS and RD were derived by bootstrapping with resampling at the level of seabird species. We used the "boot" library of A. Canty and B. Ripley in $\mathrm{R}$ (available online), ${ }^{8}$ and used the biascorrected accelerated percentile (BCa) intervals. Confidence intervals for the SC values were derived by a jackknife procedure (Efron and Tibshirani 1993) in

\footnotetext{
${ }^{8}\langle$ http://cran.r-project.org/web/packages/boot/index.html $\rangle$
}

which the standard errors were calculated by removing one seabird species at a time from the correlation matrix.

Small sample size will affect the variation of the $r_{s t}$ values. Accordingly, relatively small effective sample sizes on the year-to-year and habitat scales were expected to increase the RD values. Moreover, due to measurement error and non-synoptical measurements, more noise was linked to the responses on the local patch level. The $r_{s t}$ values and correlation among seabirds were therefore expected to be weaker on this level. Differences in the various response measures across scales should therefore be interpreted cautiously.

\section{RESUlts}

Two-stage models.-Summary of the two-stage analyses of the different species groups is given in Appendix B: Table B1. Estimates of yearly abundance indices are shown in Appendix B: Fig. B1, and maps showing the predicted spatial distributions are given in Appendix B: Fig. B2 and Fig. B3.

Spatial and temporal pattern.-The spatial autocorrelograms for seabirds, fish and zooplankton are shown in Fig. 2. For the data, the autocorrelograms indicated large-scale spatial structures with positive correlations for scales up to about $300-400 \mathrm{~km}$ for seabirds and fish, and more than $400 \mathrm{~km}$ for zooplankton. The spatial correlograms of the residuals still indicated the existence of spatial structures. However, the strength of the autocorrelation and the scales of the structures had decreased.

To investigate the temporal stability of the spatial structures, we computed temporal autocorrelograms (Fig. 3). For seabirds and zooplankton, the correlation decreased for increasing timelag. For the data, there was still a positive correlation between years, confirming the existence of a persistent spatial pattern among years. For the residuals, the temporal autocorrelations were generally weaker, and the correlations between years were closer to zero, indicating that the models had accounted for a substantial part of the average large-scale pattern. Moreover, for seabirds and zooplankton, the autocorrelation of the residuals decreased rapidly within the first 10 days, and leveled out thereafter, indicating relatively short-lived spatial structures.

Response diversity.- On the year-to-year scale, the seabirds showed a clear pattern in the response to the different prey species (Fig. 4A). On average, the yearly winter abundance of seabirds in the North Sea was positively related to the abundance of herring $\left(\bar{r}_{t}=0.31\right.$ \pm 0.08 [mean $\pm \mathrm{SE}])$, Para/pseudocalanus $(0.29 \pm 0.06)$ and Calanus helgolandicus $(0.26 \pm 0.08)$, and negatively related to the abundance of krill $(-0.34 \pm 0.05)$. The different prey groups explained accordingly a significant portion of the variance in the responses (one-way ANOVA; $\left.F_{5,54}=9.98, P<0.001\right)$. The similar responses among seabird species resulted in a relatively low response diversity (Fig. 5A), a strong average 

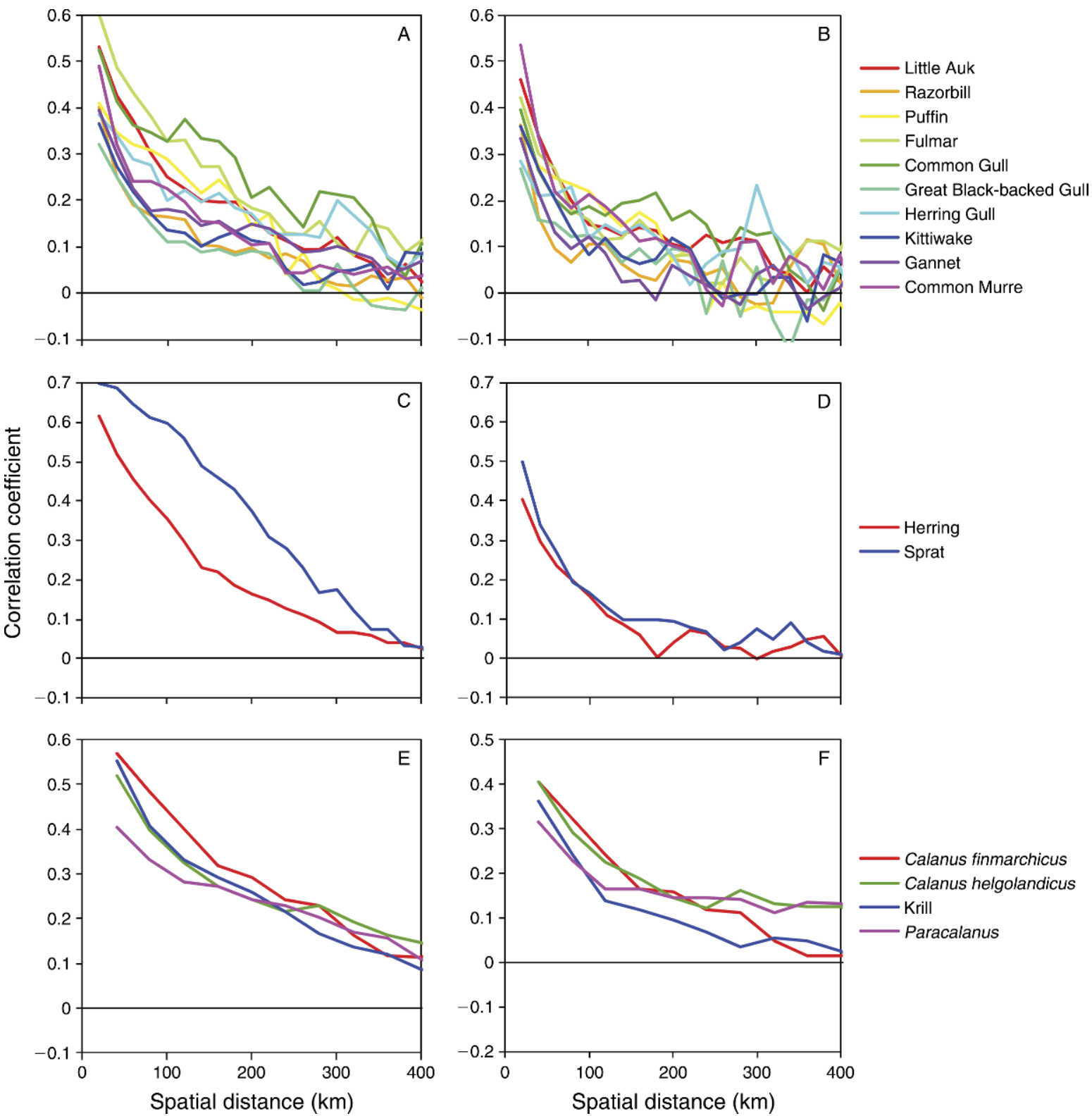

FIG. 2. (A, C, E) Spatial autocorrelograms of data and (B, D, F) residuals from the two-stage models for (A, B) seabirds, (C, D) pelagic fish, and (E, F) zooplankton. "Correlation coefficient" is Pearson's product moment correlation coefficient between pair of observations as a function of distance. Maximum time lag between observations was set to 6 days.

response (Fig. 5B), and a high average correlation in the abundance of seabirds among years (Fig. 5C).

On the habitat scale, no clear pattern with respect to the responses to different prey groups could be detected (Fig. 4B). Thus, contrary to the year-to-year scale, the different prey groups could not explain a significant portion of the variance in the responses (one-way ANOVA; $F_{5,54}=0.77, P=0.58$ ). Instead, the different seabird species were found in partly nonoverlapping habitats (cf. Appendix B: Fig. B2) dominated by different prey groups (cf. Appendix B: Fig. B3) resulting in a range of responses to each prey group (Fig. 4B). Note that a positive response to a prey group on the year-to-year scale did not imply a positive overlap to the same prey group on the habitat scale (Fig. 4A, B). For example, the abundance of little auks was positively related to the abundance of herring on the year-to-year scale however, they were clearly segregated (negative response) on the habitat scale. Accordingly, there was no significant relationship between the responses on the habitat and year-to-year scale (linear regression: habitat $r_{s t}=0.08-$ 0.14 (year-to-year $r_{s t}$ ), $R^{2}=0.01, F_{1,58}=0.77, P=0.38$ ). 

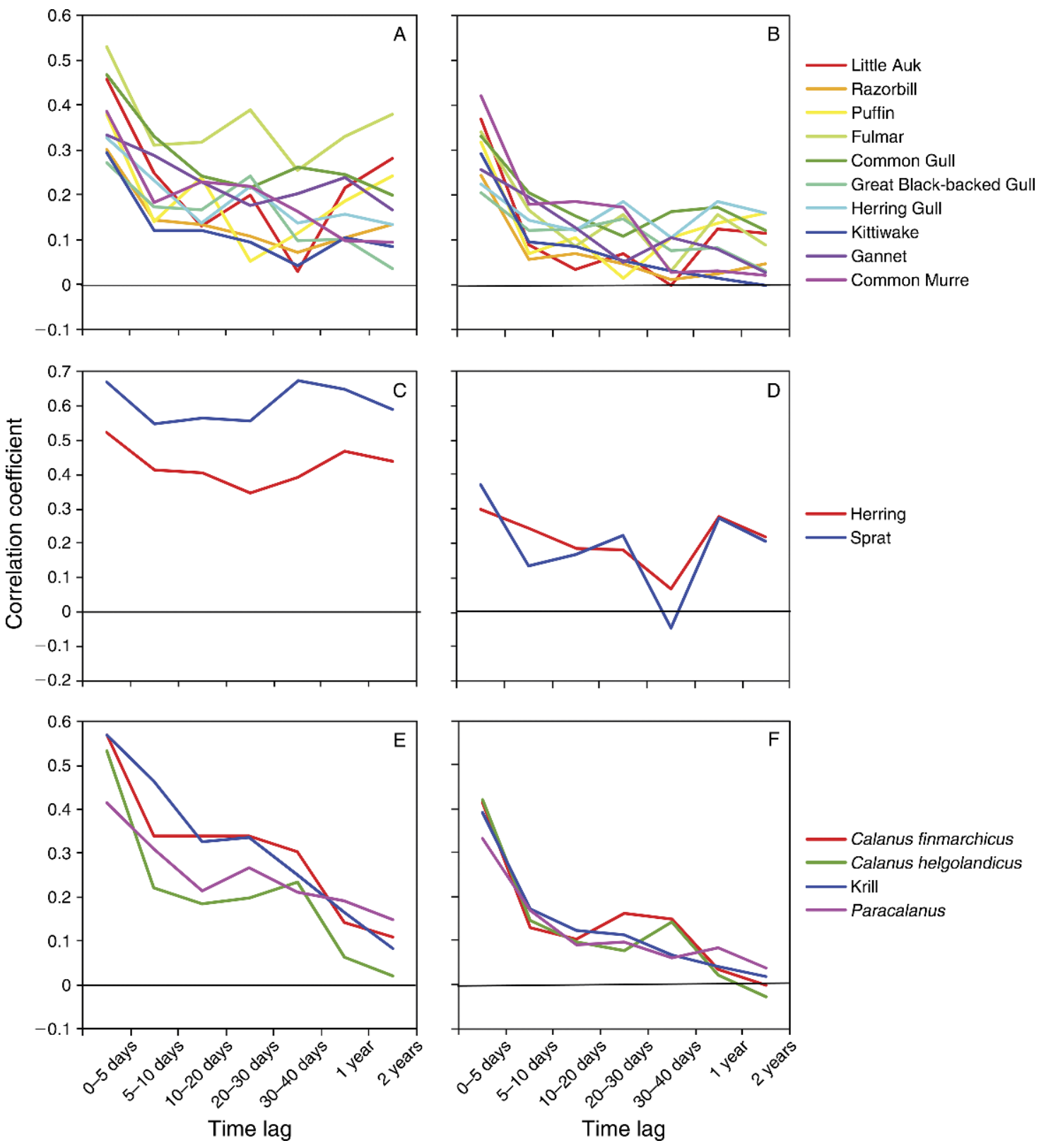

Fig. 3. (A, C, E) Temporal autocorrelograms of data and (B, D, F) residuals from the two-stage models: (A, B) seabirds, (C, D) pelagic fish, and (E, F) zooplankton. "Correlation coefficient" is Pearson's product moment correlation coefficient between pair of observations as a function of time lag. Maximum spatial distance between observations was set to $50 \mathrm{~km}$.

Habitat segregation resulted in a relatively high response diversity (Fig. 5A). Because opposite responses leveled each other out, the average response strength was relatively low (Fig. 5B). The average correlation (i.e., overlap) among seabird habitats was positive but not significantly different from zero (Fig. 5C).

The spatial responses of seabirds to prey were weak on the local patch scale ( $r_{s t}$ range -0.25 to 0.11 , Fig. 4 C). The spatial structures in the residuals of seabirds and prey (cf. Figs. 2 and 3) were in other words neither segregated nor overlapping. The different prey groups could not explain a significant portion of the variance in the responses (one-way ANOVA; $F_{5,54}=1.19, P=0.33$ ), and there were no significant relationship between the responses on the local patch scale and the responses on the habitat scale (linear regression: patch $r_{s t}=-0.01-$ 0.02 (habitat $r_{s t}$ ), $R^{2}=0.01, F_{1,58}=0.57, P=0.45$ ) nor on the year-to-year scale (linear regression: patch $r_{s t}=$ $-0.01-0.01$ (year-to-year $r_{s t}$ ), $R^{2}=0.00, F_{1,58}=0.06, P$ $=0.81)$. Thus, on the local patch scale, the average response strength was weak (Fig. 5B), and the response diversity was low (Fig. 5A). It should be noted that due 
to measurement errors and non-synoptical data, the responses on the local patch level were expected to be weak. However, the presence of distinct spatial patterns in the residuals combined with a relatively large sample size, suggests that the existence of significant responses should have been detected by the analyses. Instead there was on average a significant positive spatial overlap among the different seabird species (Fig. 5C), suggesting that interactions among seabirds were important for pattern formation at this scale.

\section{DisCUSSION}

This study demonstrates that the response diversity of seabirds to prey changes across scales of ecological organization in the North Sea ecosystem (Fig. 5). On the year-to-year scale we found a synchronous response of seabirds to the abundance of prey. On the habitat scale, the diversity in the response to prey showed a marked increase as different seabird species were found in habitats dominated by different prey species. Finally, on the local patch scale, seabirds were organized in multispecies patches. We were however, unable to detect any spatial response of seabirds to patches of prey. The observed change in response diversity, response strength and correlation across scales suggest that different ecological processes dominated on the different scales of organization.

Ecological similarities among species within a functional group would indicate that they, at some level of ecological organization, should respond similarly to environmental heterogeneity. The changes in the breeding populations of North Sea seabirds (Dunnet et al. 1990, Mitchell et al. 2006) have been related to changes in the stocks of major prey items such as sandeel (Frederiksen et al. 2004) and herring (Aebischer et al. 1990), changes in climate (Frederiksen et al. 2007, 2008), and discards from fisheries (Garthe et al. 1996). How changes in the marine ecosystem affect the abundance of overwintering pelagic seabirds is, however, poorly known. The breeding populations of many seabirds in the North Sea increased during the 1970s and 1980s and have subsequently decreased during the two last decades (Dunnet et al. 1990, Mitchell et al. 2006). This general pattern is reflected by several of the time series generated in the present study (i.e., Little Auk, Common Murre, Razorbill, Fulmar, and Kittiwake; see Appendix B: Fig. B1). Note however, that Little Auk do not breed in the North Sea. Major changes took place in the North Sea ecosystem during the 1980s. These included changes in the plankton community and the recruitment of important fish stocks, and have largely been related to climate forcing (e.g., Beaugrand 2004, Alheit et al. 2005). It is likely that the ecosystem changes also affected the profitability of the North Sea as a winter area for seabirds, with large variations in the abundance of seabirds as a consequence (cf. Appendix B: Fig. B1). Interestingly, the different seabird species seemed to have similar responses; high abundance of seabirds was found in years with high density of herring and Calanus helgolandicus and low density of krill. However, complex interactions among ecosystem components might generate spurious correlations. For example climate might affect both the recruitment of pelagic fish and the abundance of zooplankton (e.g., Beaugrand 2004), or harvesting might cascade down the food web resulting in inverse relationships between pelagic fish and zooplankton (e.g., Frank et al. 2005). Our results indicate that such changes have affected the number of wintering seabirds in the North Sea; however, the direct cause for the synchronous change is difficult to assess.

At some scales, interspecific competition among coexisting species within a functional group should be reflected by niche segregation, and thus differential responses to environmental heterogeneity. Due to different adaptations, different seabird species are associated with different parts of the pelagic ecosystem (Abrams 1985, Harrison et al. 1994, Ballance et al. 1997, Vilchis et al. 2006). Ballance et al. (1997) suggested that the spatial segregation of seabirds in the eastern tropical Pacific was related to morphological trade-offs between competitive and foraging abilities. Clearly, the present study suggests that although the different species had similar responses to prey abundance at the year-to-year scale, they responded differently to the spatial distribution of prey on the habitat scale. Response diversity was consequently high and the overlap of seabird habitats was relatively low. We suggest that this result reflects different adaptation and niche utilization among different seabird species.

On the local patch scale, the spatial relationship between seabirds and prey is determined by the ability of seabirds to aggregate on concentrations of prey and the ability of prey to avoid areas of high predation risk (reviewed in Fauchald 2009). Depending on how predators and prey are spatially constrained, this spatial behavioral response race (Lima 2002) can result in negative, zero, or positive spatial association between predators and prey (Sih 2005). Seabirds in the North Sea were apparently unable to effectively track the patches of prey, as we found no spatial association between patches of seabirds and prey. We found, however, a spatial association among the different seabird species, suggesting that seabirds, despite differential spatial organization on the habitat scale, were organized in multispecies patches. The lack of environmental correlates suggests that self-organizing mechanisms related to facilitation might be important for pattern formation among seabirds at this scale (Camphuysen and Webb 1999, Fauchald 2009). One facilitating mechanism that can produce the observed pattern is "local enhancement" (Camphuysen and Webb 1999, Grünbaum and Veit 2003). This mechanism assumes that it is easier for a seabird to detect foraging conspecifics than it is to detect prey patches directly. Depending on the asymmetry in the detectability of prey vs. other foragers, local enhancement will produce a highly aggregated spatial distribu- 

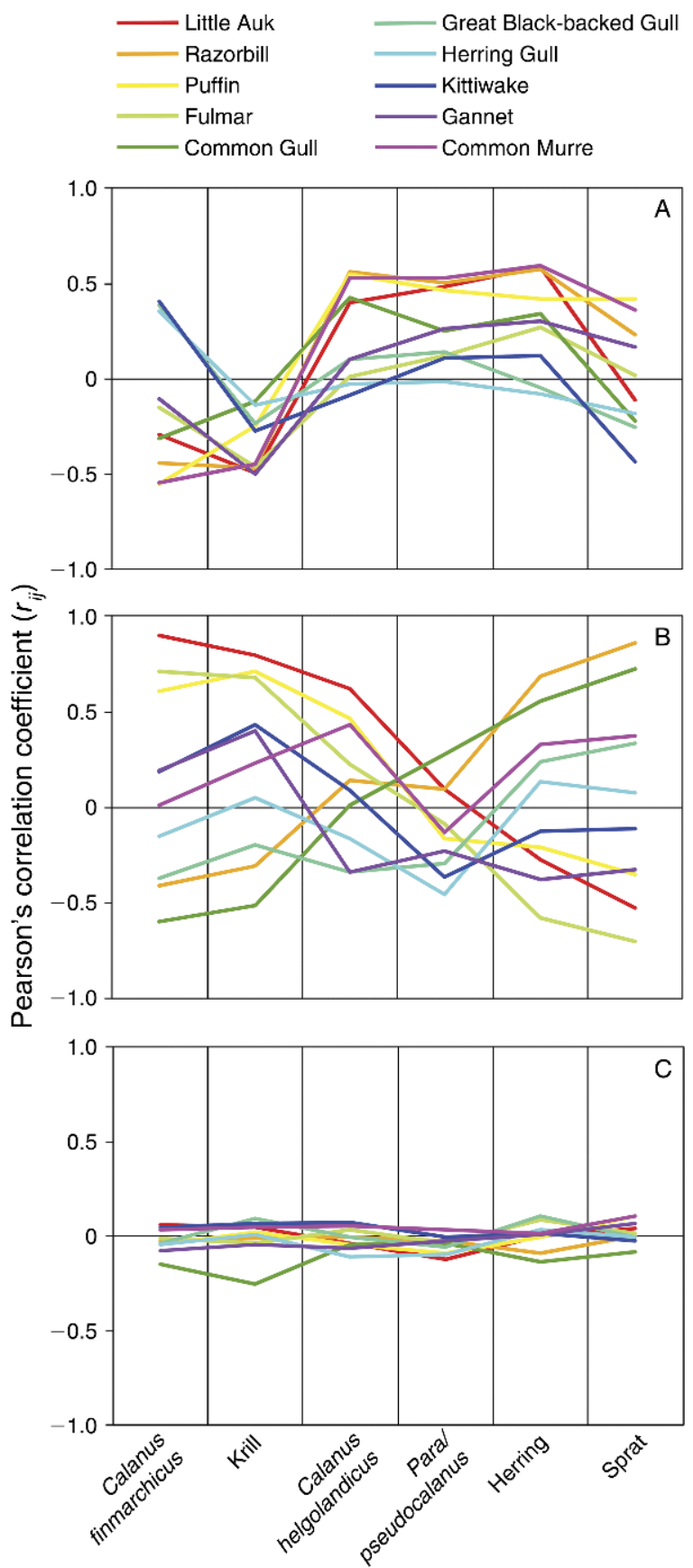

FIG. 4. The responses of 10 different seabird species to the density of six different prey groups in the North Sea on three levels of ecological organization. (A) Year-to-year scale: relationships between yearly abundance estimates of seabirds and prey. (B) Habitat scale: relationships between the average spatial distributions of seabirds and prey. (C) Local patch scale: relationships between the spatial distribution of seabirds and prey within years.

tion of predators. Accordingly, intense predation will be concentrated at a few resource patches while many patches will be free from predators. Combined with the escape response in the pelagic schooling fishes, this will produce a highly elusive and patchy system where patches of predators chase patches of prey and where the spatial association between the two is highly ephemeral. Moreover, different species might have different roles in multispecies seabird aggregations (e.g., Hoffman et al. 1981, Camphuysen and Webb 1999). While surface feeding birds such as kittiwake might be important in detecting other foraging seabirds and prey, deep-diving seabirds such as Murres might be important in driving prey to the surface (Camphuysen and Webb 1999).

While our study suggests that ephemeral associations between seabirds and schooling fish prevail in the open parts of the North Sea during winter, it should be borne
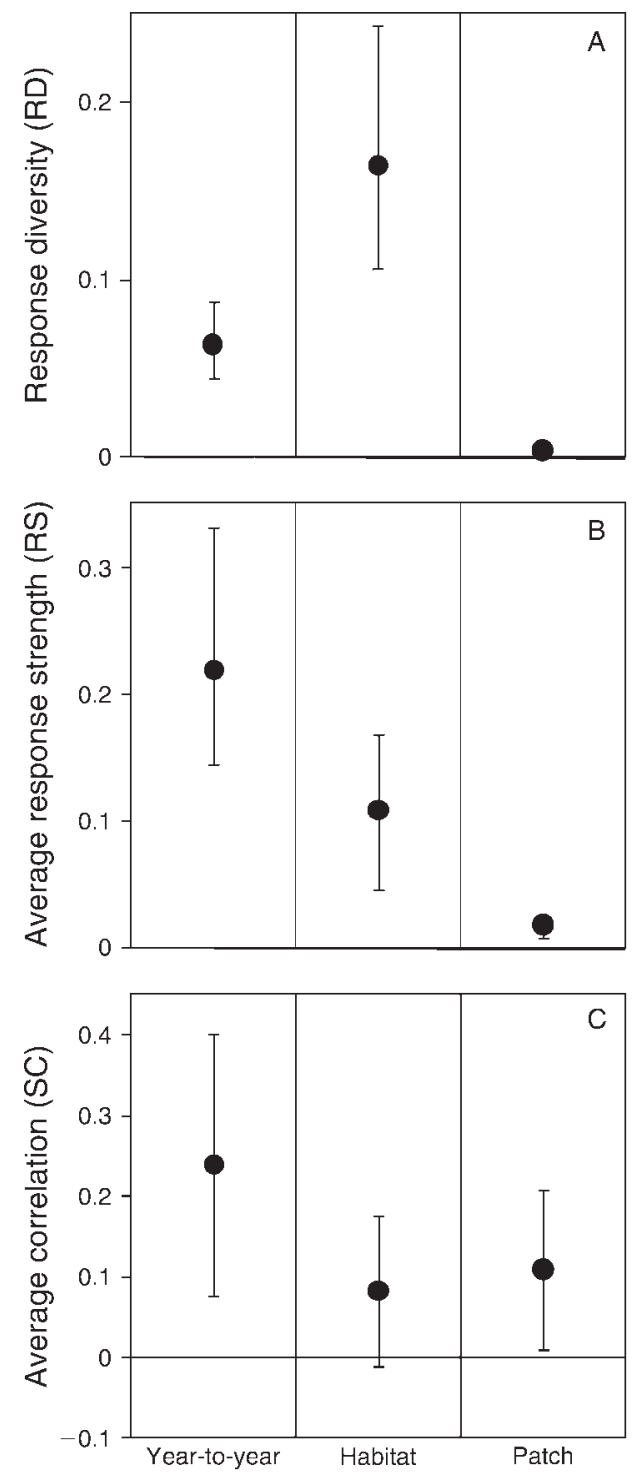

FIG. 5. (A) Response diversity and (B) response strength of seabirds to prey in the North Sea on three different scales of ecological organization. (C) Synchrony in the density among seabird species. Error bars represent $95 \%$ confidence intervals. See Methods for definitions. 
in mind that the spatial scale at which the shift in response diversity from the habitat to the patch scale took place, could only be established in broad terms. A general characteristic of seabird patches seems to be the formation of extended aggregations, rather than patches formed by single or few flocks, as indicated by flattopped rather than spiked abundance curves (Schneider and Duffy 1985). Elaborate analyses of the scaledependent intensity of aggregation of different species of seabirds have documented maximum values at the scale of 10-50 km (Schneider and Duffy 1985, Briggs et al. 1987). Analyses of patterns of response between the habitat and the patch scale should therefore be pursued to establish the degree of niche segregation in the North Sea at this intermediate scale.

The observed scale dependencies in response strength and diversity will certainly influence how seabirds will respond to environmental disturbances. Harvesting of top predators and climate change have large impact on plankton and pelagic fishes in marine ecosystems (Beaugrand 2004, Frank et al. 2005). Our results suggest that due to low response diversity on the year-to-year scale, such changes might have similar impact on different seabird species. On the contrary, due to spatial segregation on the habitat scale, spatially restricted disturbances such as oil pollution or by-catch in fishing gears will affect some species more adversely than others. Finally, the present study suggests that facilitation might be important on the local patch scale. Facilitation will make seabirds sensitive to a reduction in the abundance of the most important facilitating species. Thus, a reduction in the abundance of "key" species such as, e.g., Kittiwakes or Common Murres (Camphuysen and Webb 1999) might have detrimental effects on the rest of the seabird community. This could in fact offer a potential cross-scale explanation for the low response diversity on the year-to-year scale; one or a few important facilitating species might potentially dictate the profitability of the North Sea as a winter area to the rest of the seabird species.

In conclusion, the present study demonstrates that the diversity in responses of a functional group to a set of environmental variables can change across scales. This might be due to the fact that different ecological processes prevail on different spatial and temporal scales. For the seabirds in the North Sea this will have large consequences for how different environmental disturbances such as climate change, over-fishing and oil pollution will affect the seabird community.

\section{ACKNOWLEDGMENTS}

We thank Maria Zarecki for kindly providing the data from the ICES database. This study was a part of the project BARSPAT financed by the Research Council of Norway.

\section{Literature Cited}

Abrams, R. W. 1985. Environmental determinants of pelagic seabird distribution in the African sector of the southern ocean. Journal of Biogeography 12:473-492.
Aebischer, N. J., J. C. Coulson, and J. M. Colebrook. 1990. Parallel long-term trends across four marine trophic levels and weather. Nature 347:753-755.

Alheit, J., and E. Hagen. 1997. Long-term climate forcing of European herring and sardine populations. Fisheries Oceanography 6:130-139.

Alheit, J., C. Möllmann, J. Dutz, G. Kornilovs, P. Loewe, V. Mohrholz, and N. Wasmund. 2005. Synchronous ecological regime shifts in the central Baltic and the North Sea in the late 1980s. ICES Journal of Marine Science 62:1205-1215.

Ballance, L. T., R. L. Pitman, and S. B. Reilly. 1997. Seabird community structure along a productivity gradient: Importance of competition and energetic constraint. Ecology 78: $1502-1518$

Barry, S. C., and A. H. Welsh. 2002. Generalized additive modelling and zero inflated count data. Ecological Modelling 157:179-188.

Beaugrand, G. 2004. The North Sea regime shift: evidence, causes, mechanisms and consequences. Progress in Oceanography $60: 245-262$.

Bradstreet, M. S. W., and R. G. B. Brown. 1985. Feeding ecology of the Atlantic Alcidae. Pages 264-318 in D. N. Nettleship and T. R. Birkhead, editors. The Atlantic Alcidae. Academic Press, London, UK.

Briggs, K. T., W. B. Tyler, D. B. Lewis, and D. R. Carlson. 1987. Bird communities at sea off California: 1975-1983. Avian Biology 11:1-74.

Camphuysen, C. J. 1990. Fish stocks, fisheries and seabirds in the North Sea. Feasibility study for a detailed analysis of interactions between fish stocks, fisheries and wintering seabirds. Technisch Rapport Vogelbescherming 5. Vogelbescherming Nederland, Zeist, The Netherlands.

Camphuysen, K., and A. Webb. 1999. Multi-species feeding associations in North Sea seabirds: jointly exploiting a patchy environment. Ardea 87:177-198.

Ciannelli, L., P. Fauchald, K. S. Chan, V. N. Agostini, and G. E. Dingsor. 2008. Spatial fisheries ecology: recent progress and future prospects. Journal of Marine Systems 71:223-236.

Cramp, S., and K. E. L. Simmons. 1977. Handbook of the birds of Europe, the Middle East, and North Africa: the birds of the western Palearctic. Volume 1. Oxford University Press, Oxford, UK

Dunnet, G. M., R. W. Furness, M. L. Tasker, and P. H. Becker. 1990. Seabird ecology in the North Sea. Netherlands Journal of Sea Research 26:387-425.

Efron, B., and R. J. Tibshirani. 1993. An introduction to the bootstrap. Chapman and Hall, New York, New York, USA.

Elmqvist, T., C. Folke, M. Nystrom, G. Peterson, J. Bengtsson, B. Walker, and J. Norberg. 2003. Response diversity, ecosystem change, and resilience. Frontiers in Ecology and the Environment 1:488-494.

Fauchald, P. 2009. The spatial interaction between seabirds and prey: a review and synthesis. Marine Ecology Progress Series 391:139-151.

Fauchald, P., K. E. Erikstad, and H. Skarsfjord. 2000. Scaledependent predator-prey interactions: the hierarchical spatial distribution of seabirds and prey. Ecology 81:773-783.

Fauchald, P., and T. Tveraa. 2006. Hierarchical patch dynamics and animal movement pattern. Oecologia 149:383-395.

Folke, C., S. Carpenter, B. Walker, M. Scheffer, T. Elmqvist, L. Gunderson, and C. S. Holling. 2004. Regime shifts, resilience, and biodiversity in ecosystem management. Annual Review of Ecology, Evolution, and Systematics 35:557-581.

Fox, C. J., C. M. O'Brien, M. Dickey-Collas, and R. D. M. Nash. 2000. Patterns in the spawning of cod (Gadus morhua L.), sole (Solea solea L.) and plaice (Pleuronectes platessa L.) in the Irish Sea as determined by generalized additive modelling. Fisheries Oceanography 9:33-49.

Frank, K. T., B. Petrie, J. S. Choi, and W. C. Leggett. 2005. Trophic cascades in a formerly cod-dominated ecosystem. Science 308:1621-1623. 
Frederiksen, M., F. Daunt, M. P. Harris, and S. Wanless. 2008. The demographic impact of extreme events: stochastic weather drives survival and population dynamics in a longlived seabird. Journal of Animal Ecology 77:1020-1029.

Frederiksen, M., M. Edwards, R. A. Mavor, and S. Wanless. 2007. Regional and annual variation in Black-legged Kittiwake breeding productivity is related to sea surface temperature. Marine Ecology Progress Series 350:137-143.

Frederiksen, M., S. Wanless, P. Rothery, and L. J. Wilson. 2004. The role of industrial fisheries and oceanographic change in the decline of North Sea Black-legged Kittiwakes. Journal of Applied Ecology 41:1129-1139.

Frederiksen, M., P. J. Wright, M. P. Harris, R. A. Mavor, M. Heubeck, and S. Wanless. 2005. Regional patterns of Kittiwake Rissa tridactyla breeding success are related to variability in sandeel recruitment. Marine Ecology Progress Series 300:201-211.

Garthe, S., C. J. Camphuysen, and R. W. Furness. 1996. Amounts of discards by commercial fisheries and their significance as food for seabirds in the North Sea. Marine Ecology Progress Series 136:1-11.

Grünbaum, D., and R. R. Veit. 2003. Black-browed Albatrosses foraging on Antarctic krill: density-dependence through local enhancement? Ecology 84:3265-3275.

Harrison, N. M., A. Webb, and G. M. Leaper. 1994. Patterns of seabird distribution west of Scotland. Aquatic Conservation Marine and Freshwater Ecosystems 4:21-30.

Hoffman, W., D. Heinemann, and J. A. Wiens. 1981. The ecology of seabird feeding flocks in Alaska. Auk 98:437-456.

Holling, C. S. 1992. Cross-scale morphology, geometry, and dynamics of ecosystems. Ecological Monographs 62:447-502.

Hooper, D. U., et al. 2005. Effects of biodiversity on ecosystem functioning: a consensus of current knowledge. Ecological Monographs 75:3-35.

ICES (International Council for the Exploration of the Sea). 2004. Manual for the international bottom trawl surveys, revision VII. The International Bottom Trawl Survey Working Group. International Council for the Exploration of the Sea (ICES), Copenhagen, Denmark.

ICES (International Council for the Exploration of the Sea). 2007. Report of the ICES Advisory Committee on Fishery Management, Advisory Committee on the Marine Environment and Advisory Committee on Ecosystems, 2007. International Council for the Exploration of the Sea (ICES), Copenhagen, Denmark.

Kirkerud, K. 1989. Object oriented Programming with SIMULA. Addison-Wesley Publishing Company, Wokingham, UK.

Levin, S. A. 1992. The problem of pattern and scale in ecology. Ecology 73:1943-1967.

Lima, S. L. 2002. Putting predators back into behavioral predator-prey interactions. Trends in Ecology and Evolution 17:70-75.

Lindley, J. A. 1982. Continuous plankton records: geographical variations in numerical abundance, biomass and production of Euphausiids in the North Atlantic Ocean and the North Sea. Marine Biology 71:7-10.
Loreau, M., S. Naeem, P. Inchausti, J. Bengtsson, J. P. Grime, A. Hector, D. U. Hooper, M. A. Huston, D. Raffaelli, B. Schmid, D. Tilman, and D. A. Wardle. 2001. Ecology: biodiversity and ecosystem functioning. Current knowledge and future challenges. Science 294:804-808.

Mitchell, P. I., S. F. Newton, N. R. Ratcliffe, and T. E. Dunn. 2006. Seabird populations of Britain and Ireland: the last 30 years. Pages 765-766 in G. C. Boere, C. A. Galbraith, and D. A. Stroud, editors. Waterbirds around the world. Stationery Office, Edinburgh, UK.

Naeem, S. 1998. Species redundancy and ecosystem reliability. Conservation Biology 12:39-45.

Naeem, S. 2002. Ecosystem consequences of biodiversity loss: the evolution of a paradigm. Ecology 83:1537-1552.

Pimm, S. L. 1982. Food webs. Chapman and Hall, London, UK.

R Development Core Team. 2009. R: a language and environment for statistical computing. R Foundation for Statistical Computing, Vienna, Austria. 〈http://www. R-project.org $\rangle$

Richardson, A. J., A. W. Walne, A. W. G. John, T. D. Jonas, J. A. Lindley, D. W. Sims, D. Stevens, and M. Witt. 2006. Using continuous plankton recorder data. Progress in Oceanography 68:27-74.

Sala, O. E., et al. 2000. Biodiversity: global biodiversity scenarios for the year 2100. Science 287:1770-1774.

Schneider, D. C., and D. C. Duffy. 1985. Scale-dependent variability in seabird abundance. Marine Ecology Progress Series 25:211-218.

Sih, A. 2005. Predator-prey space use as an emergent outcome of a behavioral response race. Pages 240-255 in P. Barbosa and I. Castellanos, editors. Ecology of predator-prey interactions. Oxford University Press, New York, New York, USA.

Skov, H., J. Durinck, and P. Andell. 2000. Associations between wintering avian predators and schooling fish in the Skagerrak-Kattegat suggest reliance on predictable aggregations of herring Clupea harengus. Journal of Avian Biology 31:135-143.

Tasker, M. L., O. Hope Jones, T. Dixon, and B. F. Blake. 1984. Counting seabirds from ships: a review of methods employed and a suggestion for a standardized approach. Auk 101:567577.

Vilchis, L. I., L. T. Ballance, and P. C. Fiedler. 2006. Pelagic habitat of seabirds in the eastern tropical Pacific: effects of foraging ecology on habitat selection. Marine Ecology Progress Series 315:279-292.

Welsh, A. H., R. B. Cunningham, C. F. Donnelly, and D. B. Lindenmayer. 1996. Modelling the abundance of rare species: statistical models for counts with extra zeros. Ecological Modelling 88:297-308.

Wood, S. N. 2006. Generalized additive models an introduction with R. Chapman and Hall/CRC, Boca Raton, Florida, USA.

Zuur, A. F., E. N. Ieno, N. J. Walker, A. A. Saveliev, and G. M. Smith. 2009. Mixed effects models and extensions in ecology with R. Springer, New York, New York, USA.

\section{APPENDIX A}

Summary of databases on seabirds, fish, and zooplankton (Ecological Archives E092-019-A1).

\section{APPENDIX B}

Two-stage models relating the count of each species group to year and geographically fixed variables (Ecological Archives E092019-A2). 